Article

\title{
Distribution and Risk Assessment of Potential Invasiveness of Australoheros facetus (Jenyns, 1842) in Portugal
}

\author{
Flavia Baduy $^{1}{ }^{\circledR}$, João L. Saraiva ${ }^{1}{ }^{\circledR}$, Filipe Ribeiro ${ }^{2}$, Adelino V. M. Canario ${ }^{1}{ }^{\mathbb{D}}$ and \\ Pedro M. Guerreiro ${ }^{1, *(D)}$ \\ 1 CCMAR-Centro de Ciências do Mar, Universidade do Algarve, 8005-139 Faro, Portugal; \\ flabaduy@gmail.com (F.B.); jsaraiva@ualg.pt (J.L.S.); acanario@ualg.pt (A.V.M.C.) \\ 2 MARE-Centro de Ciências do Mar e do Ambiente, Universidade de Lisboa, 1600-548 Lisboa, Portugal; \\ fmvribeiro@gmail.com \\ * Correspondence: pmgg@ualg.pt
}

Received: 1 November 2019; Accepted: 23 December 2019; Published: 27 December 2019

\begin{abstract}
Invasive species are recognized as a major cause of biodiversity decline. Legal regulations relating to the prevention, control, or eradication of invasive species should always be up-to-date, as the failure to recognize the problem, lack of adequate scientific information, or long legal intervals required to prepare the legislation may result in irreversible, possibly catastrophic, outcomes. This implies constant monitoring of the species distribution and levels of establishment, as well as detailed knowledge about its biology to predict dissemination and viability under changing environmental conditions. Pre-screening kits for potential invasive species are valuable tools for policy makers, as they provide information about if and how management measures should be taken. The Freshwater Fish Invasiveness Scoring Kit (FISK) and the Aquatic Species Invasiveness Screening Kit (AS-ISK) have been suggested as reliable tools to assess the potential risk of a species becoming invasive. The present study highlights the spread of the non-native chameleon cichlid Australoheros facetus in several streams of the major river drainages in southern Portugal and compares the fish assemblages and ecological indices in two selected sites in the Vascão and Odelouca rivers. We reviewed the current knowledge on the distribution, physiology, and behavior of A. facetus, and applied the toolkits FISK v2 and AS-ISK to this species to evaluate whether the species should be classified as invasive in Portugal. Field data show high abundance of the species in most streams and dominance in specific hotspots. The scores reached by the kits (FISK v2: 23; AS-ISK: 37) places A. facetus as a species with high potential of invasiveness and support the recent inclusion of this species in the invasive species list in Portugal (Decree-Law 92/2019), but, most of all, highlights the importance of frequent updates in both the field monitoring and the legal regulation and watch lists of invasive organisms.
\end{abstract}

Keywords: Freshwater Fish Invasiveness Screening Kit (FISK); Aquatic Species Invasiveness Screening Kit (AS-ISK); invasive species; freshwater fish; geographical distribution; biodiversity; environmental monitoring; Iberian Peninsula; Mediterranean-type rivers

\section{Introduction}

The introduction of alien species in new environments (whether intentionally or not) can lead to the establishment of thriving populations expanding their distribution and causing negative impacts to the environment, public health, and the economy, thus acquiring the status of invasive species [1-5]. Monitoring populations of non-native species is a valuable step in management programs, as it is less costly than to try to eradicate a fully dispersed species [5-7]. These programs should rely on 
sound risk analyses based on scientific, biological, and socio-economic information to be used in risk assessment, from which appropriate risk management actions related to prevention, early detection and rapid response, and control can be undertaken [8]. "What factors determine whether a species will become an invader or not?" was one of the three questions proposed by the program of the Scientific Committee on Problems of the Environment on biological invasions, in the 1980s [9]. To identify such species, profiling can be used in risk assessment, using the existing knowledge on their biology and ecological features $[8,10,11]$. In addition, it is important to clarify definitions of invasive species by asking questions with a focus in determining if impact and success are criteria to define invasive species, and if they are, specifying what kind of impact and which measure of success are to be used [12].

The Weed Risk Assessment (WRA) for terrestrial plants [13] was first developed to assess if new plant taxa imported into Australia and New Zealand could become invasive, mainly by analyzing current status of the taxon of interest in other parts of the world, its climate and environmental preferences, and biological attributes. Adaptations of the WRA were the inspiration for the development of screening modules by the U.K. Department of Environment, Food and Rural Affairs (DEFRA) for the implementation of the European Regulation on the use of non-native species in aquaculture. One of those modules was the freshwater Fish Invasiveness Screening Kit (FISK) initially introduced in 2005 [14-16].

The FISK was revised from 2008 onwards through the examination of its potential relevance and application to warm temperate and tropical regions, as well in the original temperate zone, yielding FISK v2 as a result [16,17]. The application of FISK v2 to the Iberian Peninsula [18] used a simplified protocol based on Clavero [10], with the exclusion of aspects such as detailed knowledge of the invasion pathways and the key biological features that determine invasion success. These are difficult to define and obtain, and consider mainly the early stages of invasion, whereas FISK can be built using abundance, distribution, and environmental data. The calibration of FISK v2 for the Iberian Peninsula was performed through the analysis of 89 fish species by 3 assessors knowledgeable of the local fish fauna, each one creating a receiver operating characteristic (ROC) curve used to evaluate the predictive ability of FISK to discriminate between invasive and non-invasive species [18]. From the ROC curves, the best FISK threshold reached (20.25) could distinguish between "medium risk" and "high risk sensu lato" species.

In 2016, a new toolkit was published to incorporate the "sister" screening tools of FISK (freshwater invertebrates (FI-ISK), marine invertebrates (MI-ISK), marine fish (MFISK) and amphibians (Amph-ISK)) in only one toolkit and to ensure that the protocols of the European Non-Native Species in Aquaculture Risk Assessment Scheme (ENSARS) are consistent with the minimum requirements for use with EU legislative instruments [19]. This resulted in the Aquatic Species Invasiveness Screening Kit (AS-ISK), which improves on clarity in the interpretation of questions and provides guidance and enhanced ecological applicability. In addition, six questions on how the climate change models are likely to affect the invasiveness of the assessed organisms were added to the AS-ISK toolkit. Until now, however, few studies have applied the new AS-ISK (but see [20-22]), and none were applied in the aquatic ecosystems of the Iberian Peninsula. Thus, this region lacks a precise threshold definition to discriminate between high, medium, or low risk of invasiveness.

One of the species assessed by Almeida et al. [18] to calibrate FISK v2 in the Iberian Peninsula was the chameleon cichlid Australoheros facetus, which yielded a FISK score of $19.3 \pm 5.8$ (with mean certainty factor for all the 89 species of $0.83 \pm 0.05$ ), and was classified as medium risk to become invasive. However, A. facetus was not included in the list of non-native/invasive species in the analysis proposed by Clavero [10] for the Iberian Peninsula, although its introduction status in Portugal and Spain is currently classified as "established" by FishBase (www.fishbase.org [23]). The species has long held the status of non-native, but not invasive, under Portuguese law (Decree-Law (DL) 565/1999 [24]). This status was very recently revised, and since July 2019 it is considered invasive under DL 92/2019 [25]. 
Australoheros facetus is a neotropical cichlid native to South America, in the Paraná-Paraguay system and the Uruguay basin [26]. The A. facetus populations screened in Portugal show high genetic similarity (based on cytochrome b similarity) to specimens collected in the Uruguay River [27]. It is a bentho-pelagic freshwater fish, mostly diurnal and displaying opportunistic feeding behavior, spawning in hard substrate and with bi-parental care of the eggs and fry [28-30]. Currently, it is present in several small streams and in the drainages of major rivers in southern Portugal and Spain [31,32], where it can be locally very abundant.

Despite its novel status, scientific and technical information about $A$. facetus in Portuguese rivers and the impact of its presence in Portuguese ecosystems is still scarce. As pointed out by [17], the FISK evaluation can highlight knowledge gaps in non-native species, and these gaps are especially critical for species classified as medium risk. Once identified, these gaps can be addressed through directed scientific research. The aim of the present work was therefore to provide novel information on species distribution, to discuss its potential impact by re-applying FISK v2 and applying AS-ISK to $A$. facetus with the inclusion of recent biological and ecological data for this species in Portugal, and to compare this with the previous findings [18]. In addition, the new AS-ISK toolkit was also applied. The inclusion of recent field and laboratory results support the recent update of the status of this species.

\section{Results}

\subsection{Australoheros Facetus Distribution in Southern Portugal}

The surveys carried out in this study confirmed the presence of $A$. facetus in previously highlighted sites and identified novel sites upstream of the previous range, in streams such as Foupana and Odeleite (part of the Guadiana drainage). Large populations were observed in many locations of the Odelouca River, downstream of the Odelouca Dam (western Algarve). It was also present in novel areas of the Sado River and in several of its tributaries (Figure 1). However, despite a few surveys, it was not found in the Mira River or its tributaries (Figure 1), although its presence cannot be ruled out.

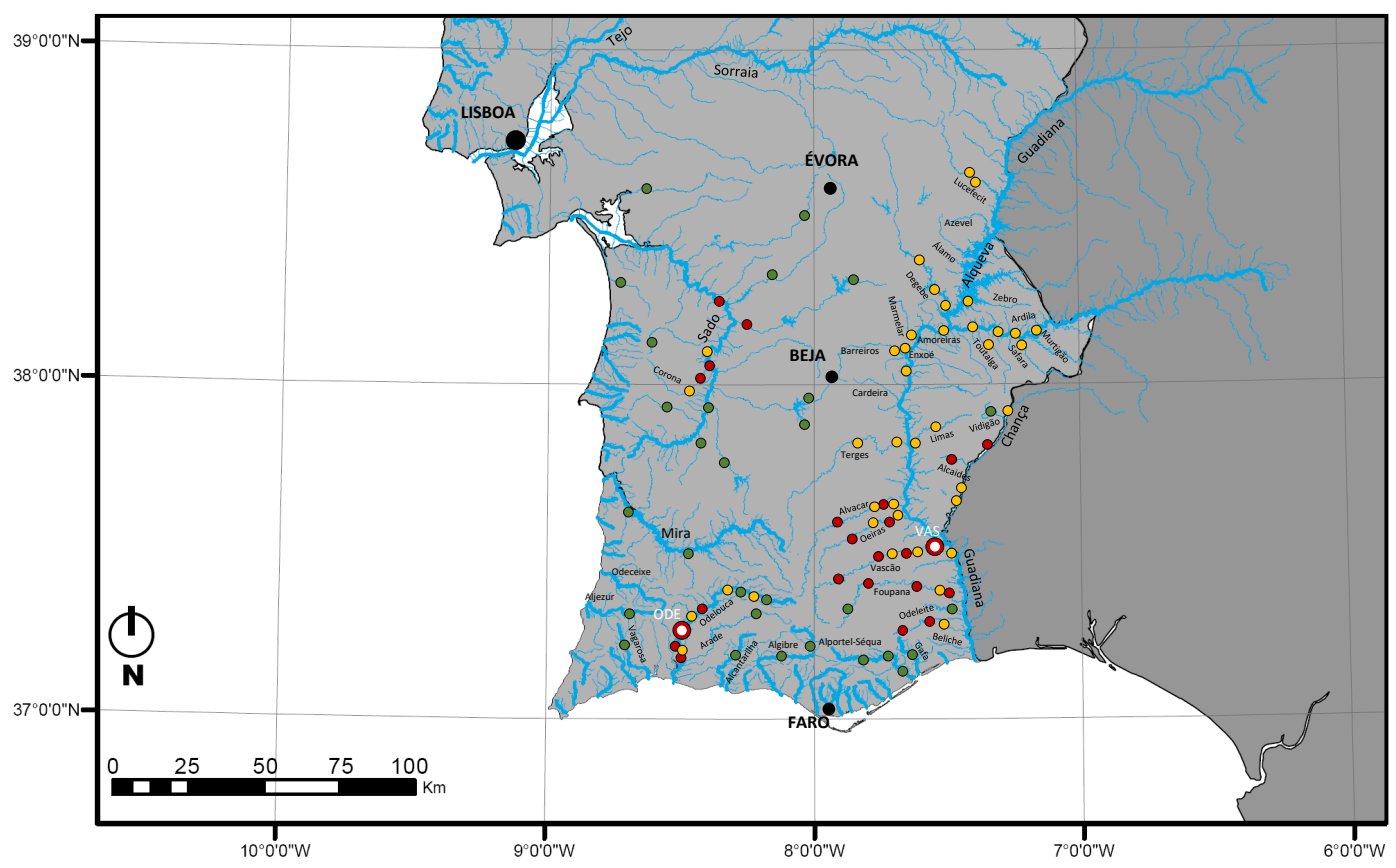

Figure 1. River drainages in southern Portugal showing the locations surveyed in the present study with presence (red) or absence (green) of Australoheros facetus. Yellow circles correspond to presence recorded in previous studies (see text). Red and white circle represent the sites used for community analysis in the Vascão (VAS) and Odelouca (ODE) rivers. 
Australoheros facetus is also present in several urban ponds and lakes, usually in public gardens and parks. This could be confirmed in Tavira, Barreiro, and Lisbon through reports made via a citizen-science platform (www.biodiversity4all.org [33]). From the same platform, there is a report of a possible sighting in Lagoa de Albufeira (north of Sado River basin), but this warrants confirmation.

\subsection{Relative Abundance of A. facetus in Fish Assemblages in Two Selected Sites}

In two selected sites at Vascão and Odelouca, A. facetus accounted for $48 \%$ and $80 \%$ of all the fish collected, respectively, in four sampling events in each site, in the autumn of 2014, 2015, 2017, and 2018 (Figure 2). However, the impact of $A$. facetus in total biomass differs greatly between the two sites. Considering the last two years alone, A. facetus represented $6 \%-8 \%$ of total fish biomass in Vascão and $80 \%-81 \%$ in Odelouca. It is, however, important to consider that, at both sites, the relative importance of the invasive mosquitofish Gambusia holbrooki was not evaluated due to the lack of resolution of the sampling methods, which resulted in ineffective capture of this species. As determined by visual inspection, the abundance of G. holbrooki in Vascão was relatively low, whereas in Odelouca it was very abundant. This could have under- and over-estimated, respectively, the relative importance of A. facetus in each assemblage. Despite the lack of information, the potential negative impacts of $G$. holbrooki in both locations cannot be disregarded, as mosquito fish are among the top invasive species in the world [34], and has been related to reductions and extinctions of native fish, including in the Iberian Peninsula, mostly due to high abiotic tolerance and favorable life-history traits reviewed by $[35,36]$.

The fish assemblage composition in the Vascão site was much more diverse than in Odelouca. Overall, a total of 15 species were recorded in Vascão, whereas 10 occurred in Odelouca, and of those 6 appeared in both locations (Table 1, Figure 2). Consequently, community indices presented consistently higher values in Vascão than in the Odelouca, underlining the A. facetus numerical dominance at the latter site (Table 1).

Table 1. Diversity indices for the Vascão $(V A S)$ and Odelouca $(O D E)$ fish assemblages. S: species number; $N$ : total fish number; $d$ : Margalef richness index; $J^{\prime}$ : Pielou evenness index; F: Fisher's alpha index; $H^{\prime}$ : Shannon index (log e); $1-\lambda$ : Simpson index; Af $n \%$ : A. facetus dominance in percentage of all fish.

\begin{tabular}{clcccccccc}
\hline YEAR & SITE & $\boldsymbol{S}$ & $\boldsymbol{N}$ & $\boldsymbol{d}$ & $\boldsymbol{J}^{\prime}$ & $\boldsymbol{F}$ & $\boldsymbol{H}^{\prime}$ & $\mathbf{1 - \lambda}$ & $\boldsymbol{A f \boldsymbol { n }} \boldsymbol{\boldsymbol { n }}$ \\
\hline \multirow{2}{*}{$\mathbf{2 0 1 4}$} & VAS & 9 & 321 & 1.39 & 0.54 & 1.72 & 1.20 & 0.59 & 0.57 \\
& ODE & 8 & 588 & 1.10 & 0.38 & 1.31 & 0.79 & 0.34 & 0.81 \\
\hline \multirow{2}{*}{$\mathbf{2 0 1 5}$} & VAS & 7 & 448 & 0.98 & 0.58 & 1.18 & 1.14 & 0.55 & 0.64 \\
& ODE & 6 & 633 & 0.78 & 0.46 & 0.92 & 0.83 & 0.39 & 0.77 \\
\hline \multirow{2}{*}{$\mathbf{2 0 1 7}$} & VAS & 11 & 249 & 1.81 & 0.70 & 2.36 & 1.69 & 0.79 & 0.24 \\
& ODE & 6 & 1193 & 0.71 & 0.39 & 0.82 & 0.71 & 0.36 & 0.79 \\
\hline \multirow{2}{*}{$\mathbf{2 0 1 8}$} & VAS & 6 & 264 & 0.90 & 0.82 & 1.09 & 1.47 & 0.74 & 0.31 \\
& ODE & 3 & 596 & 0.31 & 0.41 & 0.41 & 0.45 & 0.22 & 0.88 \\
\hline
\end{tabular}

Although the sampling dates were maintained over the years (October/November, previous to first major rain events and non-reproductive period for $A$. facetus) the composition of the fish assemblage varied considerably at each site. Although migratory or euryhaline species such as the European eel Anguilla anguilla or the thin lip mullet Liza ramada were consistently found at both sites, native cyprinids, such as barbels, nases, and chubs, showed variable presence. Luciobarbus spp. were usually present in the Vascão site but not in Odelouca. A. facetus was dominant at both sites in 2014/2015, but its presence in Vascão was much reduced in 2017/2018 - from 14.6 and $23.0 \mathrm{fish} / 100 \mathrm{~m}^{2}$ to 4.8 and 6.6 fish/100 $\mathrm{m}^{2}$, respectively, in Vascão and Odelouca. The reduction in A. facetus in Vascão was paralleled by an increase in the numbers of L. ramada and $A$. anguilla and, to a lesser extent, pumpkinseed Lepomis gibbosus. In contrast, in the Odelouca, A. facetus grew in numbers (from $66 \mathrm{fish} / 100 \mathrm{~m}^{2}$ to up to 131 fish $\left./ 100 \mathrm{~m}^{2}\right)$. 

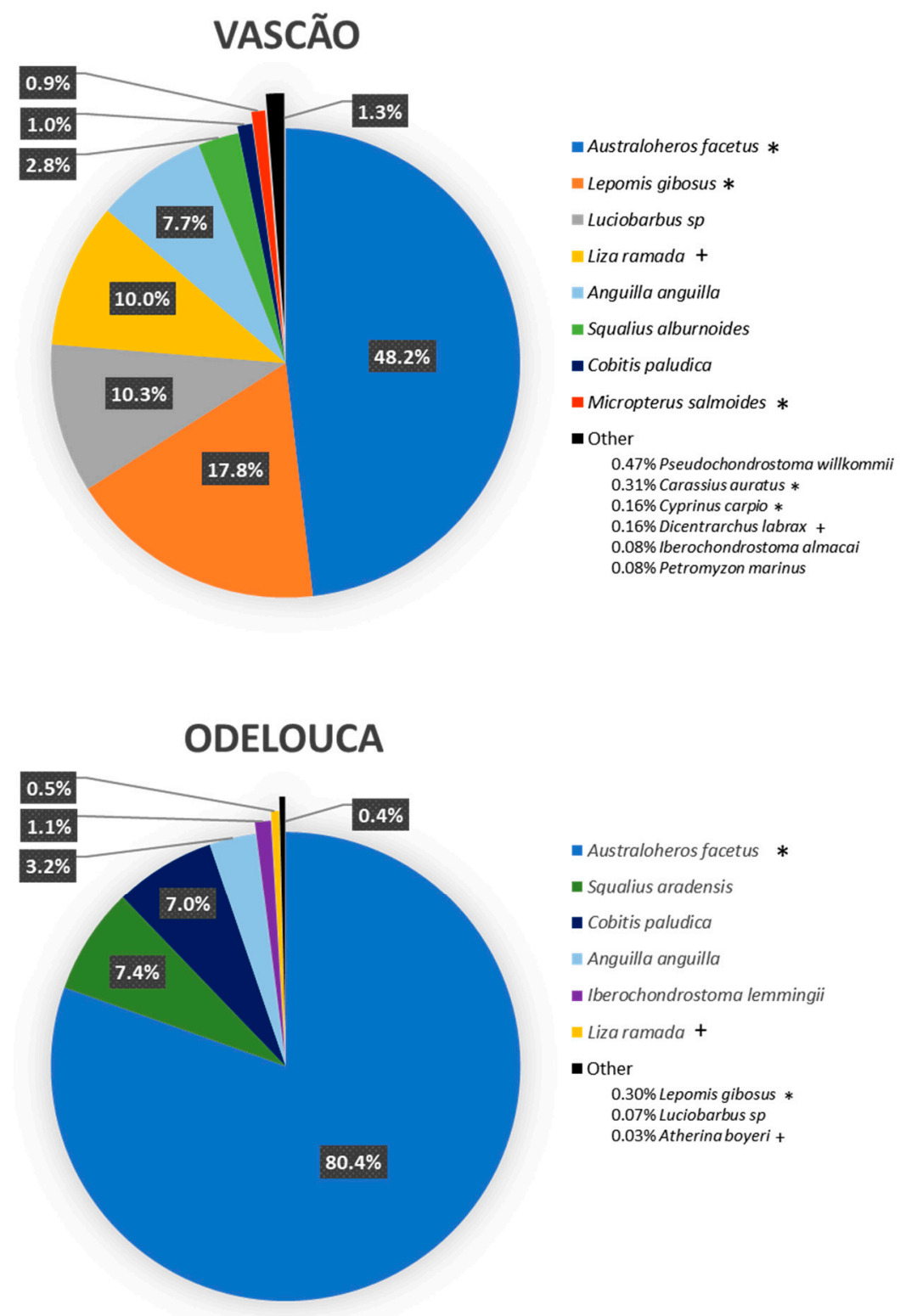

Figure 2. Relative abundance of fish species in the Vascão and Odelouca selected sites. Percentages were calculated using the sum of the individuals of each species recorded over the total number of individuals recorded in 4 years. Species with less than $0.5 \%$ of abundance were grouped as other. Asterisk $\left(^{*}\right)$ indicates non-native species and (+) indicates transient euryhaline species from marine origin.

The total length (TL) size distributions of $A$. facetus were evaluated for both sites, with overall differences in the proportion of individuals per TL size class in relation to year and not to sites (Figure 3). Given the difference in absolute number of individuals, recruitment was much higher in Odelouca, with roughly six times more individuals under $5 \mathrm{~cm}$ than Vascão in both 2017 and 2018. Furthermore, Odelouca also had a larger number of fish (eight times) above $10 \mathrm{~cm}$ than Vascão, a size at which sexual maturation is complete and fish can form reproductive pairs (Baduy et al., unpublished data). Curiously, the larger fish, that is, $>17.5 \mathrm{~cm}$, were collected in Vascão $(n=4)$ but not in Odelouca. Because A. facetus do not show sexual dimorphism outside the reproductive season, fish were not sexed. 


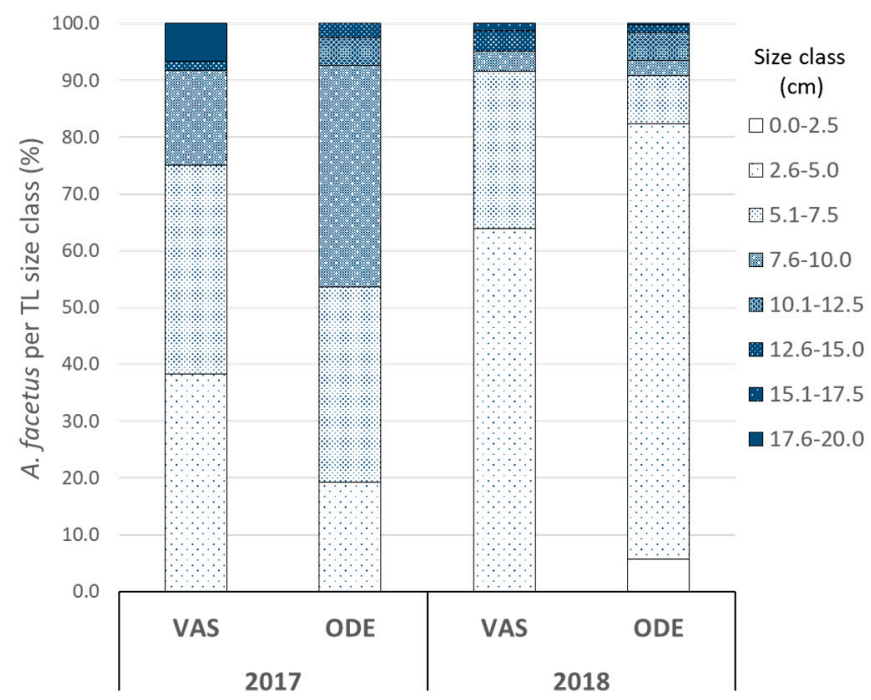

Figure 3. Variation in length distribution of Australoheros facetus in the Vascão (VAS) and Odelouca (ODE) sites collected in the autumn of 2017 and 2018. Values presented are percentages of fish per every $2.5 \mathrm{~cm}$ total length size class in relation to the total number of $A$. facetus collected. TL: total length.

\subsection{Risk Assessment Toolkits}

The FISK v2 score determined for A. facetus was 23, classifying it as a "high risk" species, in the subcategory "moderately high risk". Four toolkit questions were answered "don't know" due the scarcity of biological information. The most affected sector was "Environmental" with a score of 21 (see Supplementary File S1: Table 1).

The AS-ISK score for A. facetus was 27 for its basic risk assessment (BRA) and 10 for its climate-change assessment (CCA). The basic risk assessment (BRA) categorized A. facetus as "high risk" (threshold of 20) and the most affected sector was "Nuisance" with a score of 22 (Table 2). The change from "Aquaculture" in FISK v2 to "Commercial" in AS-ISK had some effects in the final output of the sectors affected, decreasing the impact in this sector. Similarly, the impact in the "Environmental" sector decreased, whereas the impact of "Nuisance" increased (Supplementary File S1: Table 2).

The sub-section "Feeding guild" with four questions in FISK v2 was replaced by "Resource exploitation" with just two questions in AS-ISK. This replacement made the score in this sub-section increase from 1 to 7 (Table 2, Figure 4).

Factors increasing both scores included its use as ornamental fish (domestication and cultivation), the existence of self-sustained populations outside its native range (invasive elsewhere), a climate match between the native range and the Iberian Peninsula, the wide temperature tolerance, and certain degree of euryhalinity (undesirable and persistence traits; persistence and tolerance attributes). These features are represented in Figure 4. 
Table 2. Statistical summary of Fish Invasiveness Scoring Kit (FISK) v2 and Aquatic Species Invasiveness Screening Kit (AS-ISK) scoring for A. facetus in Portugal.

\begin{tabular}{lcc}
\hline \multicolumn{1}{c}{ Scores } & FISK v2 & AS-ISK \\
\hline Total score & 23 & 37 \\
Basic risk assessment (BRA) score & 23 & 27 \\
Climate-change assessment (CCA) score & - & 10 \\
Outcome & High & High \\
\hline
\end{tabular}

Score Partition

\begin{tabular}{lll}
\hline A. Biogeography/Historical & & \\
1. Domestication/cultivation & 4 & 4 \\
2. FISK v2: climate, distribution; AS-ISK: climate, distribution, and introduction risk & 2 & 1 \\
3. Invasive elsewhere & 4 & 2 \\
B. Biology/Ecology & 5 & 6 \\
4. FISK v2: undesirable traits; AS-ISK: undesirable or persistence traits & 1 & 7 \\
5. FISK v2: feeding guild; AS-ISK: resource exploitation & 2 & 1 \\
6. Reproduction & 4 & 3 \\
7. Dispersal mechanisms & 1 & 3 \\
8. FISK v2: persistence attributes; AS-ISK: tolerance attributes & - \\
C. Climate Change & & 10 \\
9. Climate change & &
\end{tabular}

\begin{tabular}{|c|c|c|}
\hline \multicolumn{3}{|l|}{ Questions } \\
\hline Answered & 46 & 53 \\
\hline Not applicable & 3 & 2 \\
\hline \multicolumn{3}{|l|}{ A. Biogeography/Historical } \\
\hline 1. Domestication/cultivation & 3 & 3 \\
\hline 2. FISK v2: climate, distribution; AS-ISK: climate, distribution, and introduction risk & 5 & 4 \\
\hline 3. Invasive elsewhere & 5 & 4 \\
\hline \multicolumn{3}{|l|}{ B. Biology/Ecology } \\
\hline 4. FISK v2: undesirable traits; AS-ISK: undesirable or persistence traits & 12 & 12 \\
\hline 5. FISK v2: feeding guild; AS-ISK: resource exploitation & 1 & 2 \\
\hline 6. Reproduction & 7 & 7 \\
\hline 7. Dispersal mechanisms & 8 & 9 \\
\hline 8. FISK v2: persistence attributes; AS-ISK: tolerance attributes & 5 & 6 \\
\hline \multicolumn{3}{|l|}{ C. Climate Change } \\
\hline 9. Climate change & - & 6 \\
\hline \multicolumn{3}{|l|}{ Sectors Affected } \\
\hline Aquaculture (FISK v2)/commercial (AS-ISK) & 18 & 8 \\
\hline Environmental & 21 & 11 \\
\hline Nuisance & 1 & 22 \\
\hline \multicolumn{3}{|l|}{ Thresholds } \\
\hline Medium & 19 & 19 \\
\hline High & 20 & 20 \\
\hline Confidence & 0.78 & 0.78 \\
\hline
\end{tabular}




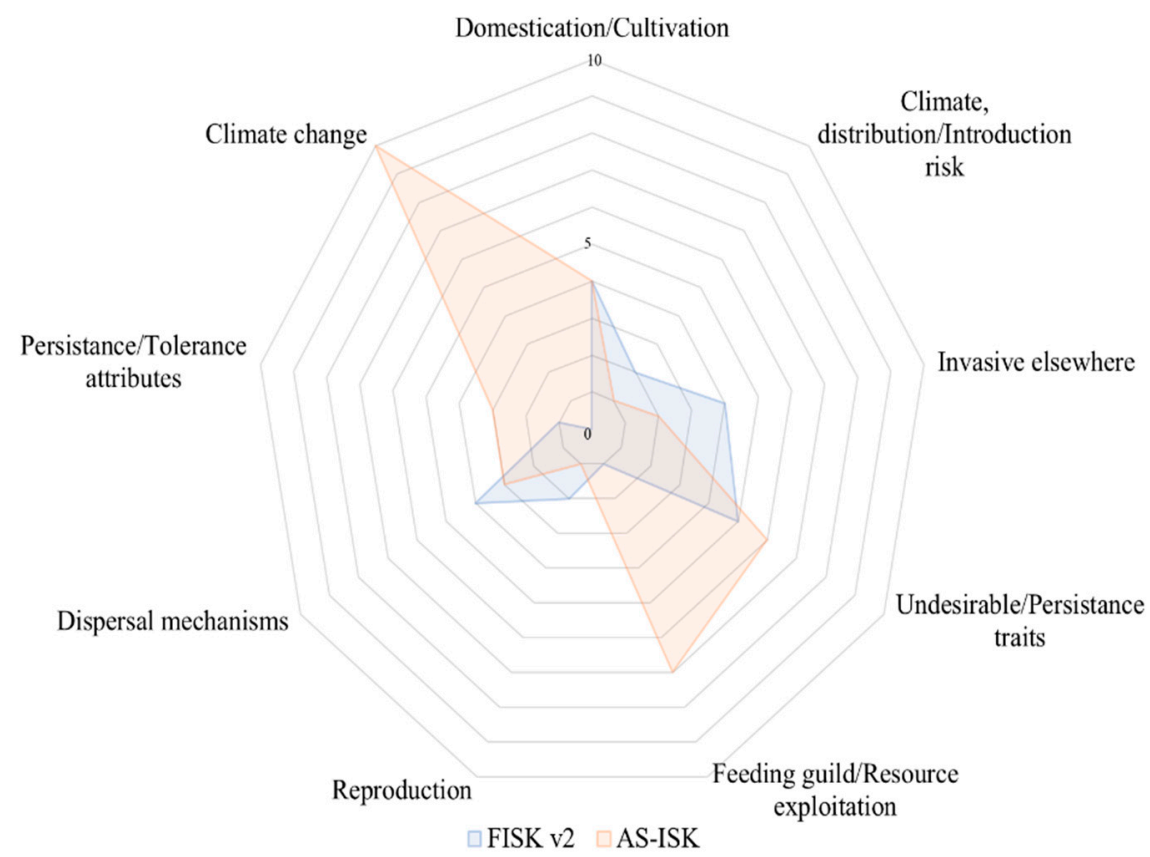

Figure 4. Radar plot showing the scores achieved by A. facetus in each attribute upon the application of the two different risk assessment kits FISK v2 (in light blue) or AS-ISK (in light orange) for Portugal. The latter takes into account the possible advantages of the species in climate-change scenarios, a parameter not considered in FISK v2.

\section{Discussion}

This study reveals an expansion in distribution of $A$. facetus in Portuguese continental waters, confirms its invasiveness, and provides context for the recent classification of the fish as an invasive species under Portuguese laws. A. facetus is now widespread in southern Portugal, covering a vast geographical area, with localized abundance hotspots in riverine systems, where it can be the dominant fish species. This work evaluated and updated the species invasion risk through the comparison of two screening kits.

\subsection{Distribution of A. facetus in Southern Portugal}

The results from our surveys performed in the last six years in southern Portugal confirmed that $A$. facetus occurs in almost all the drainages of southern Portugal (Southwestern Iberia). The Guadiana drainage is where most of the data exists and where the species appears to continue to thrive in comparison to previous surveys [29,37]. It is widespread in this drainage, occurring upstream of the Alqueva reservoir and in most of the tributaries of this drainage [29,38]. Its presence in Foupana and Guadiana has been reported by locals since at least the 1970s, and fished in shallowed waters using baited baskets and used for human consumption (personal communication). In the Sado drainage, it has expanded to the mainstream and other tributaries compared to its previously determined presence in the Corona stream [39]. The dispersal of A. facetus across the Sado River drainage is recent, given that very few localities were previously known despite its arrival in 1984 [40]. In the Algarve riverine systems, which comprise several unconnected streams not related to the Guadiana basin, A. facetus appears to be confined to the Odelouca River, where it was first reported in 1997 [41,42], pre-dating the closing of the Odelouca Dam. The construction of this artificial lake facilitated A. facetus progression due to downstream flow regulation, which changed the natural, at time torrential, riverine hydrological regime. No specimens were found in the streams either to the east or west of the Arade-Odelouca drainage. Although its presence in Mira basin, located between the Arade-Odelouca and the Sado drainages, is cited in Decree-Law 565/1999 [24], no publicly available scientific data, including from 
more recent surveys, were found to corroborate this citation and, despite several more recent surveys, the species could not be found in this drainage.

The species is present in southern Spain, not only in the Guadiana drainage but also in the Guadalquivir [32], the latter with a restricted distribution in the Seville region. The vectors for this distribution are not clear. Most likely, humans are responsible for the spreading among drainages, whereas fish movements, torrential streams, and changes of habitats by humans or human translocation may explain the distribution within a stream or drainage [40]. The high level of parental care in this species contributes to high recruitment and establishment success but, unlike for most native species, the larvae do not easily disperse to novel locations, which is confirmed by the lack of larvae collected in previous larval ecology studies [43]. In addition, the vast distribution indicates a wide tolerance to biotic and abiotic factors, a hallmark of a successful invasive species [44-47]. In Mediterranean-type streams, such as those where $A$. facetus is found, the fish assemblages are confined to pools, with low flow and loss of connectivity, increasing the pressure from competition and predation (including from terrestrial animals and the avifauna) $[48,49]$. Furthermore, abiotic conditions are extreme, with increased water temperature and reduced dissolved oxygen [29,48]. Our studies on thermal and salinity tolerance showed that $A$. facetus is highly tolerant of very high and low temperature extremes $[50,51]$ and can withstand environmental salinity at least to their isosmotic level, that is, up to 15 PSU (Practical Salinity Units) and possibly higher for smaller individuals [51,52], which may allow them to use upper estuaries as a settling point or as bridges to colonize adjacent streams. This plasticity will likely confer an advantage with the reduction of available habitats.

The results from the ecological analysis highlight the increasing abundance of $A$. facetus and the impact on the diversity of local fish populations-for example, although Vascão had greater Shannon's diversity than Odelouca throughout the study (1.14-1.69 vs. $0.45-0.83$, respectively), this difference would be minimal if non-native species were removed from the calculations, showing the great impact that non-native species can have in these fish assemblages. In other studies, the Shannon's diversity index varied between 0.3 and 1.9 in Guadiana tributaries [47] and was around 0.3 for the Arade basin [53]. Overall, the Odelouca site proved to have a poorer fish assemblage, as demonstrated by the overall ecological indices obtained over the years.

Fish assemblages in Mediterranean streams are usually characterized by the resilience of each species (migration, recolonization) rather than the local features of the habitats [53]. The dominance of native versus non-native freshwater fish species in Portugal seems to be related to seasonality and to interannual variation of pluviosity [54,55]. Usually non-native fish species dominate in dry seasons or years $[56,57]$, whereas native species dominate in wet seasons or years $[41,49,53]$. This may be relevant in a future drier climate. It is important to note that one of the sites selected is under the influence of the Odelouca dam, which maintains flowing water throughout the year and retains possible competitors, with the downstream side being rather shallow so that larger fish can only move upstream during high-water conditions. Thus, the lack of flood waters seems to favor settlement and dominance of $A$. facetus. In contrast, the Vascão site is near the river mouth, where it discharges into the much larger Guadiana river, and is under influence of tidal water movements, although these affect only the site's volume and access to the main river, but not its water salinity. This allows much larger and diverse species, such as the European sea bass, Dicentrarchus labrax, or pikeperch, Sander lucioperca, to reach the site, contributing to species richness and perhaps predating on the smaller A. facetus.

Fish abundances vary markedly between sites and season. Observations of 19 individuals/100 $\mathrm{m}^{2}$ in the Ardila River [58] and 13 individuals/100 $\mathrm{m}^{2}$ in the Vascão River [29] are consistent with our observations in the Vascão site (up to 23 individuals $/ 100 \mathrm{~m}^{2}$ ), but low compared to the Odelouca site (66-131 individuals $/ 100 \mathrm{~m}^{2}$ ). The abundance of $A$. facetus found in the Odelouca site (over 1000 in one sampling event) could be related to family groups tending to aggregate, which leads to high concentrations in relatively small areas. This species has social and parental behavior, and the reproductive pairs are highly territorial and aggressive, both to conspecifics or other species [28]. Usually, fish over $7 \mathrm{~cm}$ (SL-standard length) are physiologically able to reproduce in the wild or 
captivity, although social hierarchies may inhibit smaller individuals from reproducing (Baduy et al., personal observation). In both sites, we have observed a large number of fish under $7.5 \mathrm{~cm} \mathrm{SL}$ and only a few larger than $12.5 \mathrm{~cm} \mathrm{SL}$. Usually the larger individuals were collected far apart, and were surrounded by many smaller fish, which indicates the presence of several family groups. The frequency of sizes observed in both sites and the variation between the two years (2017 and 2018) also suggest that several broods may be produced during the reproductive season, that not all couples spawn at the same time and that the optimal time and duration for the latter may vary annually, probably depending on water conditions such as temperature, critical for the onset of the social and reproductive behavior [28].

\subsection{Evaluation of the Toolkits and Reasons for Increased Invasive Potential}

The Freshwater Fish Invasiveness Screening Kit (FISK v2) and the Aquatic Species Invasiveness Screening Kit (AS-ISK), which predict the invasive potential, were applied and updated to include the novel information. As described above, A. facetus is already present in several streams in the Guadiana, Arade, and Sado basins [27,29,42,54], where it lives in localized but abundant groups. The FISK v2 analysis with our new data yielded a score for $A$. facetus of 23-a considerable increase from the previously described 19.3 [18]. This score is particularly relevant because it upgrades the species ranking to high invasiveness risk. Furthermore, the AS-ISK score was 27 for BRA, and increased to 37 when adding its CCA.

The increase in FISK v2 score places $A$. facetus with similar potential invasiveness to the pikeperch Sander lucioperca or the tench Tinca tinca [18], despite these species having just few biological life-history traits in common (e.g., parental care in A. facetus and S. lucioperca, and extreme physiological tolerance in A. facetus and T. tinca) (Figure 5) [58]. The species most similar to A. facetus, in terms of traits such as trophic ecology, life-span, fecundity, or abiotic tolerance, is the black bullhead Ameiurus melas [59], but, interestingly, when A. melas was assessed by Almeida et al. [18], it had a FISK v2 score of 32.7, much higher than that estimated for $A$. facetus at that time. Another surprising fact is that the cichlid Astronotus ocellatus has similar life-history traits with A. facetus and, despite this, it is not established in the Iberian Peninsula, although it has a high probability of establishment (Figure 5) [58,59].

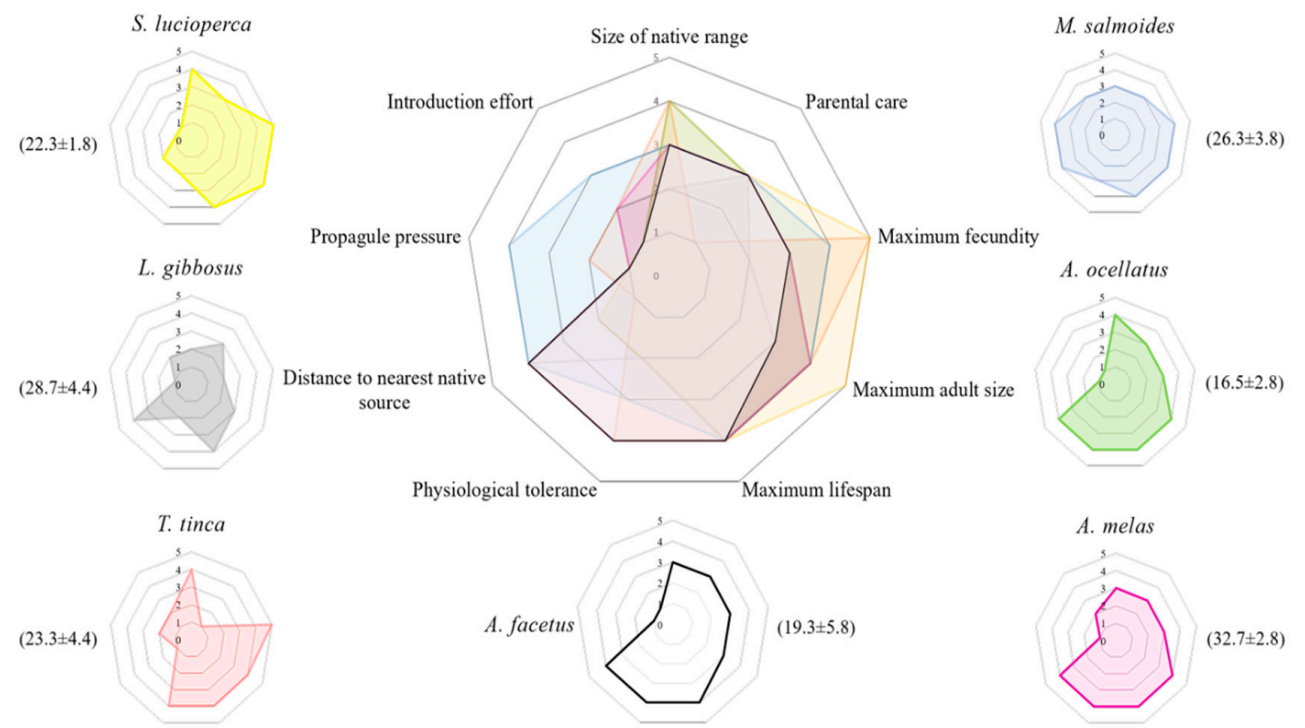

Figure 5. Scoring of biological features and life-history traits represented in radar plots built from the data assessed and provided in [57-59]. This illustration allows the comparison of each potentially advantageous trait among species. Left column: Sander lucioperca, Lepomis gibbosus, Tinca tinca; Right column: Micropterus salmoides, Astronotus ocellatus, Ameiurus melas. The central diagram superimposes each species with the representation for $A$. facetus. In parentheses are the FISK v2 scores from Almeida et al. [18]. 
Direct impacts of $A$. facetus on native species (such as the decline of native species abundance or the introduction of diseases) were not yet identified. However, there is circumstantial evidence that points to deleterious effects, with recorded activities such as feeding on the eggs or larvae of other species or displacing other fish using highly aggressive behavior $[28,29,39]$.

Although this neotropical cichlid seems to be restricted to a few basins in southern Portugal, its local abundance seems to be increasing. Despite being limited to a few sample sites, this species was dominant (abundance and biomass) in fish fauna already threatened by human activities, and poor in native but highly endemic species $[45,58,60]$. During the hot and dry summers in Mediterranean regions [61], such as southern Portugal, the fish fauna can be trapped in pools where the temperature increases rapidly and the dissolved oxygen decreases during the day, and even more at night when algae or plants are present; concomitantly, the resources diminish and, thus, the competition increases. On the other hand, water temperature during winter can reach values at least as low as $6.6^{\circ} \mathrm{C}$ (National Water Resources Information System-Portugal, available in http://snirh.pt/). The wide thermal amplitude in which $A$. facetus can live $[29,50,51]$, together with its generalist and opportunist feeding behavior $[29,39,58]$, could be a large advantage in Mediterranean streams, as it may outcompete other species during extreme events. In addition, we have shown that this species also presents salinity tolerance up to $15 \mathrm{PSU}$ and possibly higher for smaller individuals [51,52]. These appear to be examples of physiological plasticity that confers resilience to withstand abiotic variations. It remains to be seen if the species can thrive in such areas or if migrant individuals exposed to these conditions will maintain its fitness spreading throughout the invaded site.

Parental care and aggressive behavior have been also identified as key elements of successful invasions [62-64]. Aggression usually translates to dominance and brings advantage through priority access to limited resources, thus helping non-native species to acquire resources and enhance their competitiveness in a new environment. As described in Baduy et al. [28], A. facetus is particularly aggressive during the reproductive season. This may mean a competitive gain to sequester resources and quality habitats from native species, whereas its parental care allows its offspring to reach older stages, eventually to maturity, with less exposure to predation. Curiously, Ribeiro et al. [55] established that low parental care is one of the characteristics that permits a non-native species to spread within the Iberian Peninsula. As most native fishes do not have this kind of behavior, the authors concluded that having features similar to the native fishes should enhance their spread. However, Grabowska and Przybylski [63] found contrasting life-history traits among native and non-native fishes in Poland, with parental care (or some degree of) exhibited by the non-native fishes being the most distinctive feature. Therefore, A. facetus may, in fact, increase its competitive skills over the native fish fauna by differing in some biological attributes, thus taking advantage of a novel niche opportunity. Two other successful non-native species, pumpkinseed Lepomis gibbosus and largemouth bass Micropterus salmoides, both centrarchids originally from North America, present some degree of parental care, building nest sites and defending their young [65]. It is then likely that, given the common ancestry and high endemism of Iberian species in which these features were never developed, such behavior constitutes a new dimension in terms of unexplored ecological niches. Taken together, the amount of new information included in the analysis improved the species assessment, updating it and increasing the previous score [18] to a new category.

Overall, the use of the two risk assessment kits yielded similar results, indicating A. facetus as a species with high invasiveness potential. The FISK (v1 or v2) has been widely used to perform risk assessment, showing variable certainty levels across species and habitats [66], highlighting the importance of local calibration. In our case, this tool was previously calibrated to the environment $[10,18]$, and has proven to be adequate upon the introduction of novel information. The broader scope of AS-ISK simplifies the calibration process $[16,19,20]$ and has provided a similar result, with slightly higher BRA but within the same category threshold. However, the use of the CCA, specific to AS-ISK, adds a valuable dimension that allows for the prediction of the potential of the species in future 
conditions [19,67]. The latter information may provide cues on the potential for acclimation, and anticipate "winners" and "losers", as well as conditioning management plans.

\subsection{Gaps in Previous Legislation and the Recent Framework}

For the last two decades, A. facetus was classified as non-indigenous as defined in Decree-Law (DL) 565/99 [24], which regulated the introduction into nature of non-indigenous species of flora and fauna in Portugal, whereas in Spain, A. facetus has been recognized as an exotic invasive fish since 2013 by Royal Decree 630/2013, which regulates the Spanish catalogue of exotic invasive species [68]. It is important to highlight that the former legislation had important ambiguities that may have led to poor management of non-indigenous species and, in fact, allowed their dispersal. A major problem was that in this DL species listed as non-native (but not invasive) were equated to natives in the drainages where they were already present. This status opened a legal door for additional spreading, as one could conclude that, for example, in the Guadiana basin, where A. facetus was already recorded [24], there were no constraints to adding additional further individuals in those basins or moving them from one stream to the other within the same drainage. In fact, until recently, it was possible to find online forums identifying the places where aquarium hobbyists could release their large specimens that have outgrown their tank size and collect new ones. Such forums have now been removed from the Internet, but such information is shared among a group of hobbyists dedicated to this species and family (e.g., Associação Portuguesa de Ciclídeos). Moreover, these two factors ((1) a legal void, and (2) great interest as ornamental species) led to a northward spread, particularly in urban lakes in public gardens of the Lisbon area. Another direct consequence of the former law would be that if the species is already in any location in the drainage it can be translocated to any other pristine site within the same drainage. The species was occasionally used for food in several places in eastern Algarve, and this may have also contributed to its introduction in several places in the Foupana and Odeleite streams. Although the general interpretation of the previous law was that $A$. facetus could not be introduced in river basins where the species was not officially listed, there was, for a long period, sound evidence of A. facetus presence in locations not included in the annex to DL 565/99. This also highlights the need for constant monitoring of the national rivers and constant updating of the databases so that novel amendments can be made to the current regulations.

The species was finally included in the invasive species list (DL 92/2019 [25], dated from 10 July 2019). This now precludes, in article 19, its collection, rearing, transport, commercialization, introduction in the wild, and restocking in any conditions and from any drainage. Individuals collected in the frame of licensed activities cannot be released back into the wild, and must be destroyed. It also states in article 18 that the invasive species list can be revised at any time and it must be evaluated at least once every six years, and article 17 adds that the list should include exotic species already considered invasive in the surrounding countries or that raise ecological concerns within the European Union. Not of less importance, it also applies the precautionary principle that should have had been used in the DL 565/99, meaning that, in lack of sufficient scientific and technical information about its impact, an exotic species should be treated with the utmost of concern.

Environmental Policy in Portugal [69] states that the environmental policies are subordinated to the principle of "Knowledge and Science", and that the diagnosis and solutions for environmental problems must come from the convergence of social and scientific knowledge. In the most recent legal framework, the inclusion of a species in the invasive list can be promoted by any citizen or institution subject to evaluation by a panel of experts. There is also a concern with the early detection and with prevention, mitigation, and eradication policies.

We express the importance of communicating state-of-the-art knowledge that can help decision-makers prioritize if, how, and where management measures should be addressed to potential invasive species, even if there is no available conclusive evidence of direct negative impacts $[44,45,70,71]$. It is also important that such management is done at the national and international levels, as in many cases, such as between Portugal and Spain, jurisdiction over the drainage encompasses more than one 
country. The present work can, therefore, be a key element in the management of Iberian freshwater basins where $A$. facetus is present, help to predict its response in climate-change scenarios, and provide information to avoid further spread of the species.

\section{Materials and Methods}

\subsection{Geographical Distribution and Community Surveys}

Fish surveys were conducted in drainages of the lower Guadiana and its tributaries from Mértola to Odeleite, the Arade-Odelouca drainage, the Sado drainage, and several of the Ribeiras do Algarve, all in the south of Portugal, between 2013 and 2018. Standard electrofishing was applied, using a Hans Grassl EL62 II apparatus (Hans Grassl GmbH, Schönau am Königssee, Germany), with identical fishing efforts, in similarly sized areas enclosed by drift nets. Fishes were collected by dipnet and placed in water containers with aeration. Total length (nearest millimeter), weight (nearest gram), and species identification were recorded. Native fishes were returned to the stream immediately after measurements were taken.

Analysis of species richness, abundance, size distribution, and biomass was carried out for two

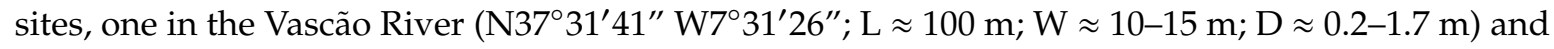
another one in the Odelouca River (N37 $14^{\prime} 49^{\prime \prime}$ W $8^{\circ} 29^{\prime} 47^{\prime \prime} ; \mathrm{L} \approx 80 \mathrm{~m} ; \mathrm{W} \approx 8-10 \mathrm{~m} ; \mathrm{D} \approx 0.2-1.4 \mathrm{~m}$ ), sampled in the autumn (October/November) of 2014, 2015, 2017, and 2018. Water temperature, salinity, and dissolved oxygen were similar at both sites $\left(16-20^{\circ} \mathrm{C} ; 0.18-0.40 \mathrm{PSU}, 8.1-10.6 \mathrm{mgO}_{2} / \mathrm{L}\right)$. Several standard biodiversity indexes (Table 1) were applied using the Primer 6 software package (version 6.1.5; PRIMER-E, Auckland, New Zealand). The likely impact of $A$. facetus was determined using its relative contribution to total fish number and biomass.

All sampling events and fish collection were made under license from the Portuguese Institute for Nature Conservancy (ICNF).

\subsection{Application of Risk Assessment Toolkits}

The FISK v2 and AS-ISK toolkits and user guide were obtained from the CEFAS website (available at http://www.cefas.co.uk [72]). FISK v2 is composed of 49 questions, divided in two Sections: (A) biogeography and historical data of the non-native species, and (B) biology and ecology, both subdivided in several items. Each question can be answered using literature searches, with a possibility to respond "don't know" if the search returned no reliable results. In addition, the assessor is asked to give a degree of certainty that leads to that answer, which weights the given answers. Thresholds for risk categories can be defined by the sum of the scoring in each section $[16,19,20,67]$. "Medium risk" species have a FISK score within the interval of $\{1$ to 19$\}$ and "high risk sensu lato" species have a FISK score within the interval of $\{20$ to 57\}. The "high risk sensu lato" species are subcategorized as "moderately high" (species with score $\{20$ to 24\}), "high" (species with score $\{25$ to 29\}), and "very high" (species with score $\{30$ to 57$\}$ ).

The AS-ISK toolkit is also composed of 49 questions that are part of the basic risk assessment (BRA) module (some of them similar to those in FISK v2) and 6 additional questions that are part of the climate-change assessment (CCA) module. As for FISK v2, the assessor is asked to provide the certainty of each answer. In AS-ISK, there is no option to respond "don't know", but there is the possibility of leaving up to five questions without an answer. As there is no available score threshold to distinguish between potentially invasive (high risk) and non-invasive (medium to low risk) for the Iberian Peninsula, the same thresholds published in Almeida et al. [17] for FISK v2 were used in the present study.

The categories of the sectors affected in FISK v2 were "Aquaculture (A)", "Environmental (E)", "Nuisance $(\mathrm{N})$ ", and "combined $(\mathrm{Cb})$ ". However, the "combined" category had no distinction of which sectors were combined, whereas for AS-ISK the sectors were categorized as "Commercial (C)", 
"Environmental (E)", and "Nuisance $(\mathrm{N})$ ", and the combinations among them were explicit (e.g., the code used for a combined "Environmental" and "Nuisance" were EN).

The questions were answered using the assessor's expertise, scientific literature search, grey literature search (e.g., reports, working papers), online discussion forums, and other "grey literature". Three assessors carried out the assessment. After completing the assessments, a report was generated with the scores for the species and corresponding certainty factor (Supplementary File S1).

Supplementary Materials: The following are available online at http://www.mdpi.com/2410-3888/5/1/3/s1. Supplementary File S1, containing the tables with the full scoring for FISK v2 and AS-ISK evaluation toolkits.

Author Contributions: Conceptualization: F.B., P.M.G., J.L.S.; methodology: F.B., P.M.G., J.L.S., F.R.; formal analysis: F.B.; investigation: F.B., F.R., P.M.G., J.L.S.; resources: A.V.M.C., P.M.G.; data curation: F.B., F.R.; writing —original draft preparation: F.B., P.M.G.; writing-review and editing: P.M.G., J.L.S., F.R., A.V.M.C. All authors have read and agreed to the published version of the manuscript.

Funding: F.B. received a doctoral fellowship from the National Council for Technological and Scientific Development of Brazil (CNPq), Program Science without Borders (245971/2012-2). This study received Portuguese national funds from FCT-Foundation for Science and Technology through project UID/Multi/04326/2013 and UID/Multi/04326/2019, and a fellowship (SFRH/BPD/67008/2009) to J.L.S. F.R. was supported by BCC fellowship through FRISK Project (FCT Ref. PTDC/AAG-MAA/0350/2014).

Acknowledgments: Distribution of the chameleon cichlid in the Sado drainage was kindly provided by colleagues P. Raposo de Almeida (UE-MARE) and C.M. Alexandre (MARE-UE). The electronic tool kits are Crown Copyright (2011-2013). As such, FISK v2 and AS-ISK are freeware and may be freely distributed provided this notice is retained. FISK v2 was developed by G.H. Copp (Cefas) in collaboration with J. Hill, L. Lawson (both University of Florida), Scott Hardin (Florida Fish and Wildlife Conservation Commission), and L. Vilizzi (Muğla Sttkı Koçman University and TÜBITAK). The VBA (Visual Basic for Applications) for Excel and computational programming of FISK v2 was undertaken by Lorenzo Vilizzi, elaborated and expanded from the VisualBasic code in the original Weed Risk Assessment (WRA) toolkit of P.C. Pheloung, P.A. Williams, and S.R. Halloy (1999)-these modifications are described in Lawson et al. (2013). The authors acknowledge the help of Carlos Carrapato (ICNF) and João Reis (CCMAR) and of several master students during the field surveys.

Conflicts of Interest: The authors declare no conflict of interest.

\section{References}

1. Casal, C.M.V. Global documentation of fish introductions: The growing crisis and recommendations for action. Biol. Invasions 2006, 8, 3-11. [CrossRef]

2. Clavero, M.; Garcia-Berthou, E. Invasive species are a leading cause of animal extinctions. Trends Ecol. Evol. 2005, 20, 110. [CrossRef] [PubMed]

3. Gallardo, B.; Clavero, M.; Sanchez, M.I.; Vila, M. Global ecological impacts of invasive species in aquatic ecosystems. Glob. Chang. Biol. 2016, 22, 151-163. [CrossRef] [PubMed]

4. International Union for Conservation of Nature. Guidelines for the Prevention of Biodiversity Loss Due to Biological Invasion; IUCN: Gland, Switzerland, 2000; p. 24.

5. Mack, R.N.; Simberloff, D.; Lonsdale, W.M.; Evans, H.; Clout, M.; Bazzaz, F.A. Biotic invasions: Causes, epidemiology, global consequences, and control. Ecol. Appl. 2002, 10, 689-710. [CrossRef]

6. Epanchin-Niell, R.S. Economics of invasive species policy and management. Biol. Invasions 2017. [CrossRef]

7. Epanchin-Niell, R.S.; Hastings, A. Controlling established invaders: Integrating economics and spread dynamics to determine optimal management. Ecol. Lett. 2010, 13, 528-541. [CrossRef]

8. Mandrak, N.E.; Cudmore, B. Risk assessment: Cornerstone of an aquatic invasive species program. Aquat. Ecosyst. Health Manag. 2015, 18, 312-320. [CrossRef]

9. Drake, J.A. Biological Invasions: A Global Perspective; Scientific Committee on Problems of the Environment: Chichester, UK; New York, NY, USA, 1989.

10. Clavero, M. Assessing the risk of freshwater fish introductions into the Iberian Peninsula. Freshw. Biol. 2011, 56, 2145-2155. [CrossRef]

11. Vila-Gispert, A.; Alcaraz, C.; Garcia-Berthou, E. Life-history traits of invasive fish in small Mediterranean streams. Biol. Invasions 2005, 7, 107-116. [CrossRef]

12. Heger, T.; Pahl, A.T.; Botta-Dukát, Z.; Gherardi, F.; Hoppe, C.; Hoste, I.; Jax, K.; Lindstrom, L.; Boets, P.; Haider, S.; et al. Conceptual frameworks and methods for advancing invasion ecology. Ambio 2013, 42, 527-540. [CrossRef] 
13. Pheloung, P.C.; Williams, P.A.; Halloy, S.R. A weed risk assessment model for use as a biosecurity tool evaluating plant introductions. J. Environ. Manag. 1999, 57, 239-251. [CrossRef]

14. Copp, G.H.; Garthwaite, R.; Gozlan, R.E. Risk identification and assessment of non-native freshwater fishes: A summary of concepts and perspectives on protocols for the UK. J. Appl. Ichthyol. 2005, 21, 371-373. [CrossRef]

15. Copp, G.H.; Britton, J.R.; Jeney, G.; Joly, J.-P.; Gherardi, F.; Gollasch, S.; Gozlan, R.E.; Jones, G.; MacLeod, A.; Midtlyng, P.J.; et al. Risk Assessment Protocols and Decision Making Tools for Use of Alien Species in Aquaculture and Stock Enhancement. In IMPASSE_Environmental Impacts of Alien Species in Aquaculture for Coordination Action Priority FP6 2005-SSP-5A, Sustainable Management of Europe's Natural Resources; Project No.: 044142; European Commission: Brussels, Belgium, 2008.

16. Copp, G.H. The Fish Invasiveness Screening Kit (FISK) for non-native freshwater fishes-A summary of current applications. Risk Anal. 2013, 33, 1394-1396. [CrossRef] [PubMed]

17. Lawson, L.L.; Hill, J.E.; Vilizzi, L.; Hardin, S.; Copp, G.H. Revisions of the Fish Invasiveness Screening Kit (FISK) for its application in warmer climatic zones, with particular reference to peninsular Florida. Risk Anal. 2013, 33, 1414-1431. [CrossRef] [PubMed]

18. Almeida, D.; Ribeiro, F.; Leunda, P.M.; Vilizzi, L.; Copp, G.H. Effectiveness of FISK, an invasiveness screening tool for non-native freshwater fishes, to perform risk identification assessments in the Iberian Peninsula. Risk Anal. 2013, 33, 1404-1413. [CrossRef]

19. Copp, G.H.; Vilizzi, L.; Tidbury, H.; Stebbing, P.; Tarkan, A.S.; Miossec, L.; Goulletquer, P. Development of a generic decision-support tool for identifying potentially invasive aquatic taxa: AS-ISK. Manag. Biol. Invasions 2016, 7, 343-350. [CrossRef]

20. Glamuzina, B.; Tutman, P.; Nikolić, V.; Vidović, Z.; Pavličević, J.; Vilizzi, L.; Copp, G.H.; Simonović, P. Comparison of taxon-specific and taxon-generic risk screening tools to identify potentially invasive non-native fishes in the river Neretva catchment (Bosnia and Herzegovina and Croatia). River Res. Appl. 2017. [CrossRef]

21. Tarkan, A.S.; Sarı, H.M.; İlhan, A.; Kurtul, I.; Vilizzi, L. Risk screening of non-native and translocated freshwater fish species in a Mediterranean-type shallow lake: Lake Marmara (West Anatolia). Zool. Middle East 2016, 63, 48-57. [CrossRef]

22. Tarkan, A.S.; Vilizzi, L.; Top, N.; Ekmekçi, F.G.; Stebbing, P.D.; Copp, G.H. Identification of potentially invasive freshwater fishes, including translocated species, in Turkey using the Aquatic Species Invasiveness Screening Kit (AS-ISK). Int. Rev. Hydrobiol. 2017. [CrossRef]

23. FishBase. Available online: www.fishbase.org (accessed on 19 December 2019).

24. Regulamentação da Introdução na Natureza de Espécies não Indígenas em Portugal; Diário da República: Lisbon, Portuguesa, 1999. Decreto-Lei (nº 565/1999), I Séria-A, nº 295. Available online: https://data.dre.pt/eli/dec-lei/ 565/1999/12/21/p/dre/pt/html (accessed on 22 December 2019).

25. Regulamentação da Introdução na Natureza de Espécies não Indígenas em Portugal; Diário da República: Lisbon, Portuguesa, 2019. Decreto-Lei (n ${ }^{\circ}$ 92/2019), $1^{a}$ Séria, $n^{\circ}$ 130. Available online: https://data.dre.pt/eli/dec-lei/ 92/2019/07/10/p/dre (accessed on 22 December 2019).

26. Rícan, O.; Kullander, S.O. Character- and tree-based delimitation of species in the 'Cichlasoma' facetum group (Teleostei, Cichlidae) with the description of a new genus. J. Zool. Syst. Evol. Res. 2006, 44, 136-152. [CrossRef]

27. Carecho, J.; Baduy, F.; Guerreiro, P.M.; Saraiva, J.L.; Ribeiro, F.; Verissímo, A. Taxonomic re-evaluation of the non-native cichlid in Portuguese drainages. Fishes Mediterr. Environ. 2018, 1, 12. [CrossRef]

28. Baduy, F.; Guerreiro, P.M.; Canário, A.V.; Saraiva, J.L. Social organization and endocrine profiles of Australoheros facetus, an exotic freshwater fish in southern Portugal. Acta Ethologica 2017. [CrossRef]

29. Ribeiro, F.; Orjuela, R.L.; Magalhães, M.F.; Collares-Pereira, M.J. Variability in feeding ecology of a South American cichlid: A reason for successful invasion in mediterranean-type rivers? Ecol. Freshw. Fish 2008, 16, 559-569. [CrossRef]

30. Ruiz, V.H.R.; Moyano, H.G.; Marchant, M.S.M. Aspectos biologicos del pez exotico Cichlasoma facetum (Jenyns, 1842) (Pisces, Cichlidae) en aguas dulces de Concepcion. Bol. Soc. Biol. Concepc. 1992, 63, 193-201.

31. Leunda, P.M. Impacts of non-native fishes on Iberian freshwater ichthyofauna: Current knowledge and gaps. Aquat. Invasions 2010, 5, 239-262. [CrossRef]

32. Sáez-Gómez, P.; Prenda, J. Updating the distribution data of recently introduced freshwater fish in the Guadalquivir River Basin (Spain). Bioinvasions Rec. 2019, 8. [CrossRef] 
33. BioDiversit4All. Available online: www.biodiversity4all.org (accessed on 28 October 2019).

34. Pyke, G.H. Plague Minnow or Mosquito Fish? A Review of the Biology and Impacts of Introduced Gambusia Species. Annu. Rev. Ecol. Evol. Syst. 2008, 39, 171-191. [CrossRef]

35. Ruiz-Navarro, A.; Verdiell-Cubedo, D.; Torralva, M.; Oliva-Paterna, F.J. Removal control of the highly invasive fish Gambusia holbrooki and effects on its population biology: Learning by doing. Wildl. Res. 2013, 40,82-89. [CrossRef]

36. Cano-Rocabayera, O.; de Sostoa, A.; Coll, L.; Maceda-Veiga, A. Managing small, highly prolific invasive aquatic species: Exploring anecosystem approach for the eastern mosquitofish (Gambusia holbrooki). Sci. Total Environ. 2019, 673, 594-604. [CrossRef]

37. Hermoso, V.; Clavero, M.; Blanco-Garrido, F.; Prenda, J. Invasive species and habitat degradation in Iberian streams: An analysis of their role in freshwater fish diversity loss. Ecol. Appl. 2011, 21, 175-188. [CrossRef]

38. Ribeiro, F.; Chaves, M.L.; Marques, T.A.; Da Costa, L.M. First record of Ameiurus melas (Siluriformes, Ictaluridae) in the Alqueva reservoir, Guadiana basin (Portugal). Cybium 2006, 30, 283-284.

39. Kodde, A.; Gkenas, C.; Cheoo, G.; Ribeiro, F.; Magalhães, M.F. Univited dinner guests: The effect of invasive fish and temperature on the foraging efficiency of Southern Iberian Chub. Fishes Mediterr. Environ. 2016, 11, 3 .

40. Ribeiro, F.; Collares-Pereira, M.J.; Moyle, P.B. Non-native fish in the fresh waters of Portugal, Azores and Madeira Islands: A growing threat to aquatic biodiversity. Fish. Manag. Ecol. 2009, 16, 255-2637. [CrossRef]

41. Pires, A.M.; Da Costa, L.M.; Alves, M.J.; Coelho, M.M. Fish assemblage structure across the Arade basin (southern Portugal). Cybium 2004, 28, 357-365.

42. Pires, D.F.; Pires, A.M.; Collares-Pereira, M.J.; Magalhaes, M.F. Variation in fish assemblages across dry-season pools in a Mediterranean stream: Effects of pool morphology, physicochemical factors and spatial context. Ecol. Freshw. Fish 2010, 19, 74-86. [CrossRef]

43. Ribeiro, F.; Magalhães, M.F.; Collares-Pereira, M.J. Spatial and temporal variation in assemblage structure of fish larvae in mediterranean-type streams: Contrasts between native and non-native species. Environ. Biol. Fishes 2013, 96, 467-480. [CrossRef]

44. García-Berthou, E. The characteristics of invasive fishes: What has been learned so far? J. Fish Biol. 2007, 71, 33-55. [CrossRef]

45. Anastácio, P.M.; Ribeiro, F.; Capinha, C.; Banha, F.; Gama, M.; Filipe, A.F.; Rebelo, R.; Sousa, R. Non-native freshwater fauna in Portugal: A review. Sci. Total Environ. 2019, 650, 1923-1934. [CrossRef]

46. Carveth, C.J.; Widmer, A.M.; Bonar, S.A. Comparison of upper thermal tolerances of native and non-native fish species in Arizona. Trans. Am. Fish. Soc. 2001, 135, 1433-1440. [CrossRef]

47. Gutierre, S.M.M.; Schofield, P.J.; Prodocimo, V. Salinity and temperature tolerance of an emergent alien species, the Amazon fish Astronotus ocellatus. Hydrobiologia 2016, 777, 21-31. [CrossRef]

48. Pires, A.M.; Cowx, I.G.; Coelho, M.M. Seasonal changes in fish community structure of intermittent streams in the middle reaches of the Guadiana basin, Portugal. J. Fish Biol. 1999, 54, 235-249. [CrossRef]

49. Magalhaes, M.F.; Beja, P.; Canas, C.; Collares-Pereira, M.J. Functional heterogeneity of dry-season fish refugia across a Mediterranean catchment: The role of habitat and predation. Freshw. Biol. 2002, 47, 1919-1934. [CrossRef]

50. Baduy, F.; Soares, J.; Silva, M.; Canario, A.V.M.; Saraiva, J.L.; Guerreiro, P.M. Critical thermal maximum and minimum in Australoheros facetus, a neotropical invader in the Iberian Peninsula. Fishes Mediterr. Environ. 2016, 12, 3. [CrossRef]

51. Baduy, F.; Saraiva, J.L.; Vargas, M.; Silva, M.; Soares, J.; Canário, A.V.M.; Guerreiro, P.M. Plastic physiology, social behaviour and endocrine profiles of an invasive cichlid in Southern Portugal. Adv. Comp. Endocrinol. 2016. [CrossRef]

52. Baduy, F.; Teixeira, D.; Soares, D.; Saraiva, J.L.; Canário, A.V.M.; Guerreiro, P.M. Dispersion of the invasive Australoheros facetus into upper estuaries may be deterred by salinity-related effects on both physiology and behaviour. In Proceedings of the VI Iberian Congress of Ichthyology, Murcia, Spain, 21 June 2016.

53. Matono, P.; Bernardo, J.M.; Oberdorff, T.; Ilheu, M. Effects of natural hydrological variability on fish assemblages in small Mediterranean streams: Implications for ecological assessment. Ecol. Indic. 2012, 23, 467-481. [CrossRef]

54. Alexandre, C.M.; Ferreira, T.F.; Almeida, P.R. Fish assemblages in non-regulated and regulated rivers from permanent and temporary Iberian systems. River Res. Appl. 2012. [CrossRef] 
55. Bernardo, J.M.; Ilheu, M.; Matono, P.; Costa, A.M. Interannual variation of fish assemblage structure in a Mediterranean River: Implications of streamflow on the dominance of native or exotic species. River Res. Appl. 2003, 19, 521-532. [CrossRef]

56. Godinho, F.N.; Ferreira, M.T.; Cortes, R.V. Composition and spatial organization of fish assemblages in the lower Guadiana basin, southern Iberia. Ecol. Freshw. Fish 1997, 6, 134-143. [CrossRef]

57. Ribeiro, F.; Collares-Pereira, M.J. Life-history variability of non-native centrarchids in regulated river systems of the lower River Guadiana drainage (south-west Iberian Peninsula). J. Fish Biol. 2010, 76, 522-537. [CrossRef]

58. Ribeiro, F.; Elvira, B.; Collares-Pereira, M.J.; Moyle, P.B. Life-history traits of non-native fishes in Iberian watersheds across several invasion stages: A first approach. Biol. Invasions 2008, 10, 89-102. [CrossRef]

59. Range, I.L. Applicability of Fish Risk Assessment (FISK) to Ornamental Species. Master's Thesis, University of Lisbon, Lisbon, Portugal, 2013.

60. Oliveira, J.M.; Segurado, P.; Santos, J.M.; Teixeira, A.; Ferreira, M.T.; Cortes, R.V. Modelling stream-fish functional traits in reference conditions: Regional and local environmental correlates. PLoS ONE 2012, 7. [CrossRef] [PubMed]

61. Gasith, A.; Resh, V.H. Streams in Mediterranean climate regions: Abiotic influences and biotic responses to predictable seasonal events. Annu. Rev. Ecol. Evol. Syst. 1999, 30, 51-81. [CrossRef]

62. Juette, T.; Cucherousset, J.; Cote, J. Animal personality and the ecological impacts of freshwater non-native species. Curr. Zool. 2014, 60, 417-427. [CrossRef]

63. Marchetti, M.P.; Moyle, P.B.; Levine, R. Alien fishes in California watersheds: Characteristics of successful and failed invaders. Ecol. Appl. 2004, 14, 587-596. [CrossRef]

64. Grabowska, J.; Przybylski, M. Life-history traits of non-native freshwater fish invaders differentiate them from natives in the Central European bioregion. Rev. Fish Biol. Fish. 2014, 25, 165-178. [CrossRef]

65. Colgan, P.W.; Brown, J.A. Dynamics of nest defense by male centrarchid fish. Behav. Process. 1998, 17, 17-26. [CrossRef]

66. Vilizzi, L.; Copp, G.H.; Adamovich, B.; Almeida, D.; Chan, J.; Dembski, S.; Koutsikos, N.; Magalhães, F.; Mendoza, R.; Onikura, N.; et al. A global review and meta-analysis of applications of the freshwater Fish Invasiveness Screening Kit. Rev. Fish Biol. Fish. 2019, 29, 529-568. [CrossRef]

67. Britton, J.R.; Cucherousset, J.; Davies, G.D.; Godard, M.J.; Copp, G.H. Non-nativefishes and climate change: Predicting species responses towarming temperatures in a temperate region. Freshw. Biol. 2010, 55, 1130-1141. [CrossRef]

68. Real Decreto 630/2013 del Reyno de España. Available online: https://www.boe.es/eli/es/rd/2013/08/02/630 (accessed on 1 November 2019).

69. Define as Bases da Política de Ambiente; Diário da República Lisbon, Portuguesa; Lei (nº 19/2014), I Série, $n^{\circ}$ 73. Available online: https://data.dre.pt/eli/lei/19/2014/04/14/p/dre/pt/html (accessed on 22 December 2019).

70. Hirsch, P.E.; N'Guyen, A.; Adrian-Kalchhauser, I.; Burkhardt-Holm, P. What do we really know about the impacts of one of the 100 worst invaders in Europe? A reality check. Ambio 2016, 45, 267-279. [CrossRef]

71. Ribeiro, F.; Leunda, P.M. Non-native fish impacts on Mediterranean freshwater ecosystems: Current knowledge and research needs. Fish. Manag. Ecol. 2012, 19, 142-156. [CrossRef]

72. Cefas-Centre for Environment, Fisheries and Aquaculture Science. Available online: www.cefas.co.uk (accessed on 5 February 2018).

(C) 2019 by the authors. Licensee MDPI, Basel, Switzerland. This article is an open access article distributed under the terms and conditions of the Creative Commons Attribution (CC BY) license (http://creativecommons.org/licenses/by/4.0/). 